\title{
Friendly, Humorous, Incompetent? On the Influence of Emoticons on Interpersonal Perception in the Workplace
}

\author{
Claus-Peter H. Ernst \\ Frankfurt UAS / SRH University Heidelberg \\ cernst@fb3.fra-uas.de
}

\author{
Martin Huschens \\ Johannes Gutenberg-Universität Mainz \\ huschens@uni-mainz.de
}

\begin{abstract}
Competence, humor and friendliness are good qualities to demonstrate in the workplace. We know that facial expressions provide recipients of a message with information about the senders-conveying that they possess such qualities. However, we only have limited knowledge of whether emoticons, facial expression surrogates in computer-mediated communications, do this in a similar way. Based on the four-ear model of communication and using a factorial survey, we examined how happy emoticons affect recipients' perceptions of senders' competence, humor and friendliness in the context of workplace emails. Our findings suggest that emoticon usage does not influence recipients' perceptions of senders' competence, but does influence the perception of their humor and friendliness. These findings hold practical implications: Senders can use happy emoticons to convey beneficial information at the self-revelation level of a message. Indeed, happy emoticons can make senders seem humorous and friendly to others, and does not make them seem incompetent.
\end{abstract}

\section{Introduction}

Researchers have identified several employee qualities that are beneficial in the workplace, and, hence, having these qualities can foster an employee's career. As a result, employees are very interested in knowing effective ways as to how to show their supervisors and coworkers that they have these qualities. In face-to-face communication, facial expressions provide the recipient of a message with information about the sender themselves, conveying that they possess specific qualities such as friendliness $[33,38]$. Whereas some findings suggest that in emails, emoticons can be used in a similar manner to facial expressions and influence interpersonal perception [e.g., 9], other findings suggest that there still might be differences between the effects of facial expressions in face-to-face communication and those of emoticons in computer-mediated communication [e.g., 11]. In this study, we wanted to examine the influence of happy emoticons on three qualities that are commonly accepted to be beneficial in the workplace: competence, humor, and friendliness.

Previous studies on the matter were carried out in private contexts [35] and/or used no theoretical foundations $[11,35]$. Here, with the help of the fourear model of Schulz von Thun [33], we drew on a wellestablished theory to build theoretically-justified hypotheses and use a factorial survey in a workplace setting to empirically evaluate them.

More specifically, we asked our respondents (most of which were students) to put themselves in the position of a company intern corresponding with their supervisor via email. One group was then shown an email with a happy emoticon, and another group was shown an email without a happy emoticon. Our findings suggest that happy emoticons have a significant positive influence on the recipient's perception of the sender's humor and friendliness, but that they do not have a significant influence on the recipient's perception of the sender's competence. This implies that employees can use happy emoticons in workplace emails in order to convey that they have the important qualities of humor and friendliness, to eventually foster their careers.

The paper is structured as follows: In the following section, we will introduce the four-ear model of Schulz von Thun [33] and its theoretical predecessor, the second axiom of Watzlawick et al. [38]. We will also provide the theoretical foundations of emoticon usage as text-based CMC cues. Following this, we will present our research model and research design. Finally, we will present and discuss our results before concluding our article with the limitations of our study and the implications of our results. 


\section{Theoretical background}

\subsection{The second axiom of Watzlawick}

According to Watzlawick et al. [38], human communication is characterized by five axioms: (1) One cannot not communicate; (2) every communication has a content and relationship aspect such that the latter classifies the former and is therefore a meta-communication; (3) the nature of a relationship is dependent on the punctuation of the partners' communication procedures; (4) human communication involves both digital and analogic modalities; and (5) every communication exchange is either symmetric or complementary, depending on whether it is based on equality or difference.

In the context of our study, the second of these five axioms provides particularly important insights. It postulates that communication encompasses both a content aspect and a relationship aspect that mutually complement each other. While the content aspect refers to the factual information contained in the message, the relationship aspect indirectly provides information about the sender's point of view, in terms of how the recipient is to interpret the message.

In contrast to the content aspect, which is clearly expressed by logical digital language, i.e., words and sentences, the relationship aspect is primarily conveyed through analog language. The analog forms of communication contain facial expressions, gestures, and body language as well as prosodic features that are recognizable as variations within the framework of spoken language. More specifically, prosodic features present themselves through variations of tone strength and pitch, voice, melody, and rhythm. In this respect, analog language provides information about the attitude of the sender to the conversation partner, the sender's opinion regarding the content of the message sent, and which expectations they have regarding the recipient's interpretation. In summary, the content aspect conveys pure data, while the relationship aspect specifies how this data should be interpreted [38].

\subsection{The four-ear model of Schulz von Thun}

Schulz von Thun [33] expanded on the idea of Watzlawick et al. [38] by further specifying the relationship aspect of communication. Indeed, Schulz von Thun [33] postulated that each message has an underlying anatomy that is a combination of four different communication levels at which a message can be sent and received, respectively: the factual information level, the relationship level, the selfrevelation level, and the appeal level. This model is also commonly termed the "four-ear" model, which refers to the ways in which the recipient understands (or hears) the message. The general process of communication and the four levels of a message are depicted in figure 1.

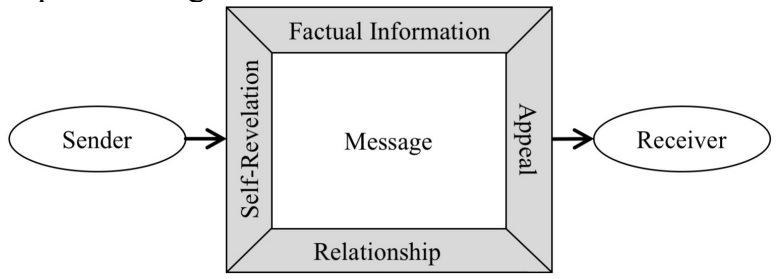

Figure 1. Communication process and four-ear model $[33$, p. 30]

At the factual information level, i.e., the content aspect of the message as defined by Watzlawick et al. [38], pure factual information is passed from the sender to the recipient. This communication layer is conveyed by the pure spoken word or the written text. At the factual information level, the recipient assesses whether a message is true or false, relevant or irrelevant, and reliable or unreliable.

Similarly to the corresponding argumentation of Watzlawick et al. [38], Schulz von Thun [33] argues that a message, besides the pure words used, inherently consists of an additional subtext or metamessage. This metamessage is only partly influenced by the pure textual information delivered by the sender. Rather, it is conveyed via non-verbal communication means, such as facial expressions, gestures, tone, speech speed and general body language, etc. However, whereas Watzlawick et al. [38] subsumes all metamessage aspects of communication under the term relationship aspect, Schulz von Thun [33] divided them into three different communication levels: the relationship level, the self-revelation level, and the appeal level.

At the self-revelation level, the sender discloses information about themselves and their current motives, values, and emotions (so called I-messages). This level is described as a small sample of personality since information about the communicator is inevitably revealed, such as what their personality is like. At the relationship level, the sender indirectly expresses a position towards the recipient (so called we-messages). Lastly, the appeal level provides information about the response expected of the recipient by the sender. This assertion suggests that the goal of messages is to produce an effect.

\subsection{Emoticons as text-based computer- mediated communication cues}

Computer-mediated communication (CMC) is now established and continues to steadily develop itself as a new form of communication. CMC can be defined as 
"[a]ny communicative transaction that takes place by way of a computer ..." [23, p. 552]. As a result, CMC can unite people via diverse channels and is particularly advantageous in that it bridges spatial and temporal barriers, thus simplifying and facilitating communication [16].

In contrast to real-life face-to-face communication, much of CMC today is founded on pure text such as emails and instant messages. In these contexts, analog language normally used to clarify messages [38] is inaccessible. As a result, a sender's ability to show emotions, for example, is limited when they engage in CMC.

Text-based elements, however, have established themselves as substitutes for these missing elements, that is, as non-verbal cues in written communication. These CMC cues can be equally effective as regular analog language [37] and are thus able to help clarify messages [36] as well as provide information about the type and strength of the emotions that the sender wishes to convey with the message [14].

One popular form of CMC cues are emoticons, i.e., text-based symbolizations of facial expressions, emotional states, and feelings [34]. ${ }^{1}$ There is a wide choice of different emoticons ranging from the simple happy face [:-)] to more sophisticated ones such as the shrugging person [־(ツ)_].

It has been shown that recipients of a message can largely identify the social and emotional meaning of an emoticon [20]. Indeed, emoticons are able to help communicate a current mood or provide information about the mental state of the sender [6, 18]. Moreover, studies have proved that emoticons serve the function of clarifying textual messages by accentuating a tone or meaning [7, 18], thus helping the sender to communicate more clearly. Several studies further examined the effects of emoticons in CMC. For example, Huang et al. [15] found that the use of emoticons in instant messaging has a positive effect on the enjoyment, personal interaction, perceived information richness, and perceived usefulness of an application.

Since CMC is not only a means of social interaction in the private domain, but also popular within professional communication in the context of companies and organizations [27], emoticons are also used in job-related communications. Indeed, Skovholt et al. [34] showed that positive emoticons in the

\footnotetext{
${ }^{1}$ In addition to text-based CMC cues, there are also pictographicbased cues such as emojis (e.g., (-), $\odot$ ). However, these are primarily being used in private communications such as in instant messaging services and on social media [cf. 22], and especially on touch-based mobile devices [29]. Since we are interested in jobrelated communication, we thus refrained from studying emojis and focused on their text-based predecessors, i.e., emoticons [22].
}

professional context provide three functions: (1) marking positive attitudes, (2) marking jokes/irony, and (3) acting as hedges, i.e., strengthening expressive speech acts (such as thanks or greetings) or softening directives and criticism (i.e., requests, rejections, corrections, and complaints).

In a different study, Luor et al. [21] examined the effects of emoticon usage in task-oriented communications in the workplace. They concluded that emoticons strengthen positive or negative feelings, especially in the case of complex communications. In addition, according to their study, there is weak evidence that women use emoticons more frequently in the workplace. Wolf [40] seemed to confirm this finding by showing that women use emoticons more frequently in the private domain.

Additionally, Ernst et al. [9] evaluated the influence of a happy emoticon on recipients' interpretations of Schulz von Thun's four communication levels [33], in the context of workplace emails expressing criticism. They found that happy emoticons exert a positive effect on the relationship level and the self-revelation level, as well as a negative effect on the appeal level. Similarly, Ernst and Huschens [8] evaluated the influence of different kinds of emoticons [:-) :-(;-)] on recipients' interpretations of the four communication levels of Schulz von Thun [33], yet again in the context of workplace emails expressing criticism. Their results suggested that happy and ironic emoticons exert a positive influence on the relationship level and the selfrevelation level. In contrast to Ernst et al. [9], they did not find a significant influence of happy emoticons on the appeal level of the message. Furthermore, their findings suggested that sad emoticons do not exert an influence on any of the four communication levels.

Another focus of emoticon research is interpersonal perception. Taesler and Janneck [35] found that emoticon usage in online chats positively influences a recipient's perception of a sender's friendliness and warmth. In contrast, Glikson et al. [11] found no influence of happy emoticons in workplace emails on the recipient's first impressions of the sender's warmth. However, they found a negative influence of happy emoticons on recipients' first impressions of senders' competence.

\section{Research model}

Being or appearing competent ${ }^{2}$, is an important quality to have in the workplace. The findings of Glikson et al. [11] suggest that the usage of happy

\footnotetext{
${ }^{2}$ Competence can be defined as "[t]he set of ... explicit and tacit knowledge [and skills] that a ... [person] possesses that enables him or her to ... [do their respective jobs]" [2, p. 164].
} 
emoticons in workplace email negatively influences the recipients' perception regarding the sender's competence. Since their study is explorative, we seek to contribute to the literature by providing a theoretical justification for the proposed relationship by drawing on the four-ear model of Schulz von Thun [33] and to replicate their finding later on in this article.

More specifically, Schulz von Thun [33] postulates that every message includes information at the selfrevelation level. At this level, senders disclose information about themselves such as their current motives, values, and emotions, and, hence, also provide information regarding what kind of person they are and their personality. It has been argued that emoticon usage harms senders' credibility in formal business contexts, and business communication guides strongly advise against emoticon usage due to their assumed inappropriateness in formal settings [18, 25]. Due to this common belief, senders' usage of emoticons may result in recipients' negative perception of senders with regard to their competence. More specifically, at the self-revelation level, recipients may come to the conclusion that the sender is unable to act appropriately within a given formal context and, hence, may be perceived as incompetent. We hypothesize the following: The usage of happy emoticons in workplace emails negatively influences the recipient's perception of the sender's competence $(\boldsymbol{H 1})$.

Besides competence, humor ${ }^{3}$ is also considered to be an important quality at the workplace. Indeed, it can be used in the workplace to reduce stress as well as to enhance leadership, group cohesiveness, communication, creativity, and organizational culture [31]. At the self-revelation level [33], a sender smiling and laughing communicates to the recipient, among other things, that they have a sense of humor. In other words, people who frequently smile and laugh are considered humorous. Indeed, it has been shown that humor is directly connected to smiling and laughing [cf. 24, 39]. Since happy emoticons are text-based symbolizations of smiles, it can be expected that their usage in workplace emails positively influences the recipient's perception of the sender's humor. We hypothesize the following: The usage of happy emoticons in workplace emails positively influences the recipient's perception of the sender's humor $(\boldsymbol{H} 2)$.

\footnotetext{
3 "Humour is defined as instances where participant(s) signal amusement to one another, based on the analyst's assessment of paralinguistic, prosodic and discoursal clues. These instances can be classified as either successful or unsuccessful according to addressees' reactions. Humour can be a result of either intentional or unintentional humorous behaviour from participants" [24, p. 21].
}

Another important employee quality that is also related to smiles is friendliness ${ }^{4}$ [4], which is especially important for customer contact persons [13]. The findings of Taesler and Janneck [35] suggest that emoticon usage in online chats positively influences recipients' perceptions of senders' friendliness. Since Taesler and Janneck's study is explorative and not placed in a workplace setting, we seek to contribute to the literature by providing a theoretical justification for the proposed relationship. We accomplished this in our study by yet again drawing on the four-ear model of Schulz von Thun [33], and replicating Taesler and Janneck's findings in a workplace setting. More specifically, other researchers have shown that smiles "produce a halo effect that correlate[s] with friendliness ..." [12, p. 469]..$^{5}$ In other words, at the self-revelation level [33], a sender smiling and laughing communicates to the recipient that they are friendly, in addition to having a sense of humor and other positive attributes [e.g., 17, 19, 28]. Since happy emoticons are text-based symbolizations of smiles, it can be expected that their usage in workplace emails positively influences the recipient's perception of the sender's friendliness. We hypothesize that: The usage of happy emoticons in workplace emails positively influences the recipient's perception of the sender's friendliness $(\boldsymbol{H} 3)$. Figure 2 summarizes our research model.

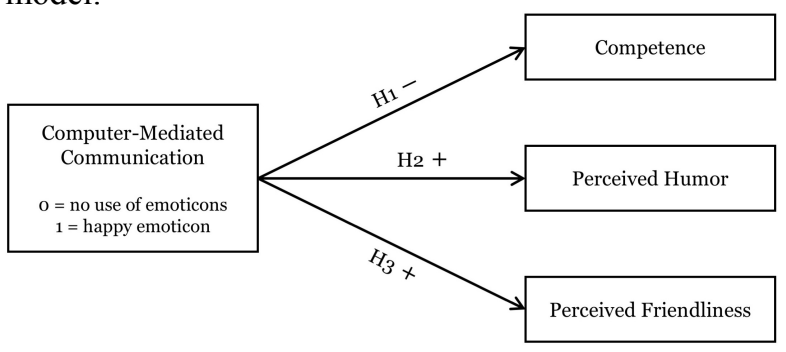

Figure 2. Research model

\section{Research design}

\subsection{Factorial survey}

To test our hypotheses, we conducted a factorial survey. "Vignette studies [also called factorial surveys [32]] combine ideas from classical experiments and survey methodology" [1, p. 128]. More specifically, vignettes are "short, carefully constructed description[s] of a person, object, or situation, representing a systematic combination of [the

\footnotetext{
${ }^{4}$ Friendliness can be understood as the quality of being friendly, i.e., having "a dispositional tendency or attitude that implies kindliness, cordiality, and goodwill" [30, p. 405].

5 "The halo effect is generally defined as the influence of a global evaluation on evaluations of individual attributes of a person ..." [26, p. 250].
} 
investigation-relevant] characteristics" [1, p. 128]. Respondents are then confronted with these different fictional situation descriptions and assess them on the basis of a questionnaire. Such situation descriptions may consist of a situational textual description, a video, illustrations or any other form of stimulation.

In our context, we asked our respondents to put themselves in the position of a company intern that corresponds with his/her supervisor via email (see table 1 for the introductory text): We used the vignette character of an intern because we expected to recruit quite a young sample of people - indeed, we posted a call on the newsboard of one German university. We assumed that students could quite easily put themselves in the position of an intern or might even have experienced such a situation themselves, which leverages the external validity of our results.

Since the defining factors of our research hypotheses are emoticons, we chose the presence and absence of a happy emoticon as the factor levels of our vignettes. As a result, we had two experimental groups: Each group received an email that was identical with regard to content and looks, but that differed with regard to the use of happy emoticons. Indeed, one email contained three happy emoticons [:-)] and one contained no emoticon at all, acting as a control (see table 1). The vignette itself was implemented as a mail client screenshot containing the message. We chose a visualized form of the vignette in order to increase closeness to reality and to strengthen the priming effect.

Furthermore, we chose to implement a betweensubjects design [1] in which subjects were randomly assigned to the treatment group or the control group. As such, every subject was only presented with one vignette situation. We believed that results from a within-subject design would have been severely flawed in our context since subjects would not have been blind to condition (i.e., the emoticon) and, thus, memory effects, sponsorship effects, and sequence effects would have come up.

Finally, in order to make sure that the vignette priming worked and that our respondents carefully read and understood the provided vignette situation, we asked them to answer three comprehension questions during the questionnaire (see table 1).

After successfully passing the situation comprehension questions, our respondents finally had to answer a questionnaire containing items for our three dependent variables. More specifically, for competence, we used three-items from Glikson et al. [11] that were measured using a seven-point Likerttype scale ranging from "strongly disagree" to "strongly agree". For perceived humor and perceived friendliness, we used Taesler and Janneck's two seven- point one-item scales [35], which had the adjectives humorless/humorous and unfriendly/friendly at their endpoints, respectively. Table 2 presents the items of our questionnaire.

\subsection{Data collection}

To empirically evaluate our research model, in May 2018, we posted a call on the newsboard of one German university and promised a raffle of four $15 €$ gift certificates for the participants. We dropped four observations from our sample since the corresponding respondents had given an incorrect answer to one of the situation-comprehension test questions. We additionally dropped two observations due to obvious answer schemes. As a result, we had a final sample size of 97 observations (53 observations in the control group and 44 observations in the treatment group).

Table 3 presents the demographics and controls of our complete sample as well as of our two subgroups, including gender, age, and current profession. As expected, our sample consisted mostly of students (89.7 percent), and, naturally, was quite young (mean: 24.00; std. dev.: 4.20). Furthermore, our sample consisted of more women (69.1 percent). According to the results of the Mann-Whitney $U$ and likelihoodratio chi-square-tests, no significant difference was detected across treatments in gender, age, and current profession. This suggests a successful random assignment of subjects to our treatment groups and supports the claim that the treatment groups did not differ with regard to these important covariates. This means we could rule out structural group differences as being the cause of any differences found in our dependent variables between groups.

\section{Results}

\subsection{Descriptives}

Table 2 below presents the descriptives per questionnaire item (mean and SD) and the average composite score for competence. We also examined the distribution properties of our two groups using Shapiro-Wilk-tests. With the exception of competence in the control group ( $\left.\mathrm{W}_{\text {Competence.CG }}=.979, \mathrm{p}=.465\right)$, all intra-group distributions were non-normally distributed.

\subsection{Hypothesis testing}

Due to the non-normality of our data as described above, we used the non-parametric Mann-Whitney U test to test for group differences [e.g., 10]. Table 4 presents the results $(*=\mathrm{p}<.001, \mathrm{~ns}=$ non-significant $)$. 
When we compared the control group with the treatment group, we found no significant difference for the recipients' perception of the sender's competence $\left(\mathrm{z}=-.966^{\mathrm{ns}}, \mathrm{p}=.334, \mathrm{r}=-.10\right)$. As a result, hypothesis 1 could not be confirmed. However, we found a medium to large treatment effect with regard to the recipients' perception of the sender's humor $(\mathrm{z}=-$ 4.600, $\mathrm{p}=.000, \mathrm{r}=-.47$ ) and a medium treatment effect with regard to the recipients' perception of the sender's friendliness $(\mathrm{z}=-3.515, \mathrm{p}=.000, \mathrm{r}=-.36)$, confirming both hypotheses 2 and 3 .

\section{Table 1. Introductory text, vignette situation, and comprehension test}

\begin{tabular}{|c|c|c|c|}
\hline & $\begin{array}{l}\text { Your name is M. Meier. You are currently } \\
\text { working as an intern at the Jansen company. } \\
\text { Your tasks include the updating of various } \\
\text { Excel spreadsheets and the scheduling of } \\
\text { meetings for your supervisor. Your last task } \\
\text { was to organize a meeting tomorrow with } 12 \\
\text { participants. You just sent the following }\end{array}$ & $\begin{array}{l}\text { Treatment } \\
\text { Group Vignette } \\
\text { Email with } \\
\text { happy } \\
\text { emoticons* }\end{array}$ & $\begin{array}{l}\text { Hello, :-) } \\
\text { Thank you for the information. Then please send the } \\
\text { report to Mrs. Schmidt after the meeting. :-) Please come } \\
\text { to the meeting tomorrow and bring the previously } \\
\text { discussed tables with you. } \\
\text { See you tomorrow :-) }\end{array}$ \\
\hline $\begin{array}{l}\text { Introductory } \\
\text { text }\end{array}$ & $\begin{array}{l}\text { regarding the next meeting: } \\
\text { Mr. Müller has just confirmed that he will } \\
\text { come to the meeting tomorrow at } 12 \text { p.m. } \\
\text { Mrs. Schmidt cannot come due to illness. } \\
\text { You can see the answer of your supervisor on } \\
\text { the following page. }\end{array}$ & $\begin{array}{l}\text { Situation } \\
\text { Comprehension } \\
\text { Test }\end{array}$ & $\begin{array}{l}\text { 1.) What is your supervisor's name? (K. Meier, A. } \\
\text { Schmittberger, L. Schmidt, J. Beinecke, A. Maus) } \\
\text { 2.) What should you bring to the meeting tomorrow? Pen } \\
\text { and paper, the discussed tables, the PowerPoint } \\
\text { presentation, a coffee, the brochures } \\
\text { 3.) Which medium do you use to communicate with your } \\
\text { supervisor? Video call, email, chat, voice call, face-to- } \\
\text { face communication (personal conversation) }\end{array}$ \\
\hline
\end{tabular}

* for our control group, we did not include any emoticons in the email

Table 2. Items and descriptives

\begin{tabular}{|c|c|c|c|c|c|c|c|c|c|}
\hline \multirow{2}{*}{$\begin{array}{l}\text { Construct (label) } \\
\text { Item (label) }\end{array}$} & \multicolumn{3}{|c|}{$\mathbf{C G}$} & \multicolumn{3}{|c|}{ TG [:-)] } & \multicolumn{3}{|c|}{$\mathbf{C S}$} \\
\hline & $\mathrm{M}$ & $\mathrm{SD}$ & Mdn & $\mathrm{M}$ & SD & Mdn & $\mathrm{M}$ & $\mathrm{SD}$ & Mdn \\
\hline Competence* $^{*}(\mathrm{C})$ & 4.41 & .91 & 4.33 & 4.73 & 1.10 & 4.33 & 4.56 & 1.01 & 4.33 \\
\hline My supervisor is professional (C1) & 4.75 & 1.16 & 5.00 & 4.09 & 1.74 & 4.00 & 4.45 & 1.48 & 5.00 \\
\hline My supervisor is committed (C2) & 4.32 & 1.24 & 4.00 & 5.27 & 1.07 & 5.00 & 4.75 & 1.25 & 5.00 \\
\hline My supervisor is capable of working effectively (C3) & 4.17 & .955 & 4.00 & 4.84 & 1.06 & 5.00 & 4.47 & 1.05 & 4.00 \\
\hline Perceived Humor (PH) & 3.53 & $\mathbf{1 . 1 5}$ & 4.00 & 4.89 & 1.62 & 5.00 & 4.14 & $\mathbf{1 . 5 3}$ & 4.00 \\
\hline My supervisor is [humorless/humorous] (PH1) & 3.53 & 1.15 & 4.00 & 4.89 & 1.62 & 5.00 & 4.14 & 1.53 & 4.00 \\
\hline Perceived Friendliness (PF) & 4.00 & 1.59 & 4.00 & 5.14 & 2.06 & 6.00 & 4.52 & 1.90 & 5.00 \\
\hline My supervisor is [unfriendly/friendly] (PF1) & 4.00 & 1.59 & 4.00 & 5.14 & 2.06 & 6.00 & 4.52 & 1.90 & 5.00 \\
\hline
\end{tabular}

$\mathrm{CG}=$ Control group, $\mathrm{TG}=$ Treatment group, $\mathrm{CS}=$ Complete sample, $\mathrm{M}=$ Mean, $\mathrm{SD}=$ standard deviation, $\mathrm{Mdn}=\mathrm{Median}$ ${ }^{*}=$ composite score per communication level, normalized with item count $(=3)$

Table 3. Demographics and controls

\begin{tabular}{|c|c|c|c|c|c|c|}
\hline & & & & & \begin{tabular}{|c} 
Mann-Wh \\
ratio \\
\end{tabular} & $\begin{array}{l}\text { likelihood- } \\
\text { re-test }\end{array}$ \\
\hline & Range & $\begin{array}{c}\mathbf{C G} \\
\mathrm{N}=53\end{array}$ & $\begin{array}{c}\text { TG [:-)] } \\
\mathrm{N}=44\end{array}$ & \begin{tabular}{|c}
$\mathbf{C S}$ \\
$\mathrm{N}=97$
\end{tabular} & $\mathrm{Z} / \chi^{2}$ & $\mathbf{p}$ \\
\hline $\begin{array}{l}\text { Age } \\
\text { Mean } \\
\text { Standard deviation }\end{array}$ & $12-41$ & $\begin{array}{c}24.40 \\
4.57 \\
\end{array}$ & $\begin{array}{c}23.52 \\
3.70 \\
\end{array}$ & $\begin{array}{c}24.00 \\
4.20 \\
\end{array}$ & $-.091^{\mathrm{a}}$ & $.928^{\mathrm{a}}$ \\
\hline Percentage of females & $0-100$ & 67.9 & 70.5 & 69.1 & $-.267^{\mathrm{a}}$ & $.789^{\mathrm{a}}$ \\
\hline $\begin{array}{l}\text { Current profession } \\
\text { Pupil } \\
\text { Apprentice } \\
\text { Student } \\
\text { Employed } \\
\end{array}$ & - & $\begin{array}{c}0 \\
0 \\
47 \\
6 \\
\end{array}$ & $\begin{array}{c}1 \\
1 \\
40 \\
2 \\
\end{array}$ & $\begin{array}{c}1 \\
1 \\
87 \\
8 \\
\end{array}$ & $4.59^{\mathrm{b}}$ & $.204^{\mathrm{b}}$ \\
\hline
\end{tabular}

$\mathrm{a}=$ Result of Mann-Whitney U test.

$b=$ Result of a likelihood-ratio chi-square-test. 


\section{Table 4. Mann-Whitney U tests}

\begin{tabular}{|l|c|c|c|}
\hline Construct & \multicolumn{1}{|c|}{$\mathbf{z}$} & $\mathbf{p}$ & $\mathbf{r}$ \\
\hline C & -.966 & $.334^{\mathrm{ns}}$ & -.10 \\
\hline $\mathrm{PH}$ & -4.600 & $.000^{*}$ & -.47 \\
\hline PF & -3.515 & $.000^{*}$ & -.36 \\
\hline
\end{tabular}

\section{Discussion}

Derks et al. [5] showed that emoticons are able to shape message interpretation. In line with this, Ernst et al. [9] found that happy emoticons influence the selfrevelation level in the context of workplace emails expressing criticism. Similarly, and in the same context, Ernst and Huschens [8] found that happy emoticons and ironic emoticons exert an influence on the self-revelation level of workplace emails.

Our results support and refine these findings. Indeed, our results suggest that happy emoticons influence the self-revelation level of workplace messages with regard to the sender's humor and friendliness.

However, whereas our result regarding friendliness is in line with the study of Taesler and Janneck [35], our result regarding humor contradicts their study, since we found a significant influence of emoticon usage on recipients' perception of the sender's humor, and Taesler and Janneck did not. We explain these different results with the different context of our study. Whereas Taesler and Janneck [35] evaluated the influence of emoticons in the context of an online chat, our study's focus was the workplace environment. Since emojis, emoticons' pictographic successors, are used more prominently in private communication than emoticons are [cf. 22], emoticons might seem outdated and, hence, no longer exert an influence in the private context as they do in the workplace. Indeed, in the workplace, emails are regularly typed on regular keyboards, making the usage of emoticons easier and more common than that of emojis.

At first sight, our findings also seem to contradict the study of Glikson et al. [11]. Whereas Glikson et al. found a negative influence of emoticons on recipients' perception of senders' competence, our data suggests no such influence. However, again, we explain these different results with the different context of our study. Indeed, Glikson et al. [11] evaluated the influence of emoticons in emails on people's virtual first impressions, i.e., the impressions people form of others who they have never had prior contact with. In contrast, our factorial survey described a situation in which prior contact between the two communicators had taken place. More specifically, the supervisor explicitly asked in their email to "bring the previously discussed tables" and we made sure that this priming had worked by asking the respondents a corresponding comprehension question regarding what they should bring to the meeting (cf. table 1). As a result, we believe that the study of Glikson et al. [11] and our study do not necessarily contradict each other, but rather that they complement each other. More specifically, taken together, our findings suggest that emoticons might influence first impressions [11], but they might not do so in communications between two people that already know each other - even if there is a certain social distance between the two individuals (as in the case of interns and supervisors).

\section{Conclusions}

In this article, we drew from the four-ear model [33] to evaluate the influence of a happy emoticon in workplace emails on recipients' perception of senders' competence, humor, and friendliness. Based on a factorial survey [32] with 97 respondents, our results confirm an influence of happy emoticons on humor and friendliness, but not on competence.

These findings hold important practical implications. Indeed, our study emphasizes that happy emoticons can be a useful means for conveying beneficial information at the self-revelation level of a message. Indeed, we showed that in the workplace context, happy emoticons can be used by employees in emails in order to make them seem humorous and friendly to others - two qualities that are considered beneficial in the workplace. In addition, employees seem not to have to worry that recipients will have a negative perception of their competence, at least when they are communicating with people they have had prior contact with [cf. 11]. Sending happy emoticons might thus be a useful means of fostering other people's positive impression of oneself, especially in distributed teams that mainly interact via IS where the members have already met.

Additionally, our findings have theoretical implications. Indeed, with the four-ear model of Schulz von Thun [33], our study introduced a well-established theory into the interpersonal perception stream of emoticon literature. Our study also suggests that the context of the workplace email interaction is very important. More specifically, taken together with the findings of other related studies [11, 35], our findings indicate that researchers need to consider the nature of 
the interaction in subsequent studies, that is, they need to determine whether it is a first-time interaction or a communication between people who already know each other.

Our study has some limitations. Certainly, a situation that is described in a vignette can never be fully realistic and is especially prone to individual misperceptions. Thus, the external validity of our study might be limited, even though we tried to select an appropriate vignette situation that fit our targeted sample. Furthermore, there is a certain social distance between the supervisor and intern in our vignettes. In a future study, it would be interesting to examine the effects of different types of social distances between the sender and recipient on the recipient's interpretation of the message. More specifically, emoticons might have a different effect on message interpretation when used between individuals with low social distance such as peers, than when used between individuals with a high social distance.

Additionally, we only used one specific vignette scenario. Although the scenario and the wording were carefully constructed, it is still possible that the respondents might have misinterpreted the emails. Indeed, the situation that was described in our fictitious scenario was not equally realistic for all respondents. For example, in the case of the employed subjects in our sample, it was maybe more difficult for them to place themselves in the role of an intern than it was for the students to do so. Nevertheless, our sample consisted mostly of students (89.7 percent), mitigating this particular limitation.

At the same time, this sample composition of mainly German-speaking subjects brings other problems with regard to our study's external validity. Indeed, our results might not hold true for non-German speaking people, and differences might also be found for other age groups.

Furthermore, there are certain limitations to between-subjects designs when it comes to perceptions, opinions and situational judgments as is the case in factorial surveys [3]. It can be argued that in between-subjects designs, each respondent judges only a single vignette, which can lead to measurement problems due to individually different vignette contexts. However, as described earlier, we think that the results from a within-subject design would be seriously flawed as subjects would not have been blind to condition, and thus memory, sponsorship and sequence effects would have come up.

Moreover, our study only included one specific incarnation of emoticons [:-)] and put only in specific places in the email messages. Hence, there might be differences for other incarnations [e.g., :)] and also for different positions of the emoticon.
Although our results hint to the fact that emoticons do not influence perception regarding competence, this result has to be replicated with other emoticons and in different situations. As a next step, we plan to do so in a controlled lab experiment, which we believe to be a promising approach for capturing the effects of emoticon usage in greater detail. Moreover, we want to include eye-tracking technology for manipulation checking, since subjects might also potentially differ with regard to the attention they give to emoticons.

Finally, in order to confirm our results, additional research must be conducted in other countries with participants of other age groups, while also including more vignettes with a greater number of emoticons and different message contents.

\section{References}

[1] C. Atzmüller, and P.M. Steiner, "Experimental Vignette Studies in Survey Research", Methodology 6 (3), 2010, pp. 128-138.

[2] G. Bassellier, B.H. Reich, and I. Benbasat, "Information Technology Competence of Business Managers: A Definition and Research Model", Journal of Management Information Systems 17 (4), 2001, pp. 159-182.

[3] M.H. Birnbaum, "How to Show That $9>221$ : Collect Judgments in a between-Subjects Design", Psychological Methods 4 (3), 1999, pp. 243-249.

[4] J. Bohatko-Naismith, C. James, M. Guest, and D.A. Rivett, "The Role of the Australian Workplace Return to Work Coordinator: Essential Qualities and Attributes", Journal of Occupational Rehabilitation 25 (1), 2015, pp. 6573.

[5] D. Derks, A.E.R. Bos, and J. von Grumbkow, "Emoticons and Online Message Interpretation", Social Science Computer Review 26 (3), 2008, pp. 379-388.

[6] D. Derks, A.H. Fischer, and A.E.R. Bos, "The Role of Emotion in Computer-Mediated Communication: A Review", Computers in Human Behavior 24 (3), 2008, pp. 766-785.

[7] E. Dresner, and S.C. Herring, "Functions of the Nonverbal in CMC: Emoticons and Illocutionary Force", Communication Theory 20 (4), 2010, pp. 249-268.

[8] C.-P.H. Ernst, and M. Huschens, "The Effects of Different Emoticons on the Perception of Emails in the Workplace", HICSS 2018 Proceedings.

[9] C.-P.H. Ernst, M. Huschens, S. Herrmann, and L. Hoppe, "The Influence of Emoticons on the Perception of JobRelated Emails: An Analysis Based on the Four-Ear Model", MKWI 2018 Proceedings. 
[10] A. Field, Discovering Statistics Using SPSS, Sage, Thousand Oaks, CA, 2009

[11] E. Glikson, A. Cheshin, and G.A. van Kleef, "The Dark Side of a Smiley: Effects of Smiling Emoticons on Virtual First Impressions", Social Psychological and Personality Science 2017.

[12] R. Godoy, V. Reyes-García, T. Huanca, S. Tanner, W.R. Leonard, T. McDade, and V. Vadez, "Do Smiles Have a Face Value? Panel Evidence from Amazonian Indians", Journal of Economic Psychology 26 (4), 2005, pp. 469-490.

[13] T. Gruber, I. Szmigin, and R. Voss, "The Desired Qualities of Customer Contact Employees in Complaint Handling Encounters", Journal of Marketing Management 22 (5-6), 2006, pp. 619-642.

[14] R.B. Harris, and D. Paradice, "An Investigation of the Computer-Mediated Communication of Emotions", Journal of Applied Sciences Research 3 (12), 2007, pp. 2081-2090.

[15] A.H. Huang, D.C. Yen, and X. Zhang, "Exploring the Potential Effects of Emoticons", Information \& Management 45 (7), 2008, pp. 466-473.

[16] S. Kiesler, and L. Sproull, "Group Decision Making and Communication Technology", Organizational Behavior and Human Decision Processes 52 (1), 1992, pp. 96-123.

[17] J. Komaki, M.R. Blood, and D. Holder, "Fostering Friendliness in a Fast Food Franchise", Journal of Organizational Behavior Management 2 (3), 1980, pp. 151164.

[18] F.B. Krohn, "A Generational Approach to Using Emoticons as Nonverbal Communication", Journal of Technical Writing and Communication 34 (4), 2004, pp. 321328 .

[19] S. Lau, "The Effect of Smiling on Person Perception", Journal of Social Psychology 117 (1), 1982, pp. 63-67.

[20] S.K. Lo, "The Nonverbal Communication Functions of Emoticons in Computer-Mediated Communication", CyberPsychology \& Behavior 11 (5), 2008, pp. 595-597.

[21] T. Luor, L.L. Wu, H.P. Lu, and Y.H. Tao, "The Effect of Emoticons in Simplex and Complex Task-Oriented Communication: An Empirical Study of Instant Messaging", Computers in Human Behavior 26 (5), 2010, pp. 889-895.

[22] D. Marengo, F. Giannotta, and M. Settanni, "Assessing Personality Using Emoji: An Exploratory Study", Personality and Individual Differences 112 2017, pp. 74-78.

[23] D. McQuail, Mcquail's Mass Communication Theory, Sage, London, UK, 2010.

[24] L. Mullany, "Gender, Politeness and Institutional Power Roles: Humour as a Tactic to Gain Compliance in Workplace
Business Meetings", Multilingua - Journal of Cross-Cultural and Interlanguage Communication 23 (1-2), 2004, pp. 13-37.

[25] M. Munter, P.S. Rogers, and J. Rymer, "Business EMail: Guidelines for Users", Business Communication Quarterly 66 (1), 2003, pp. 26-40.

[26] R.E. Nisbett, and T.D. Wilson, "The Halo Effect: Evidence for Unconscious Alteration of Judgments", Journal of Personality and Social Psychology 35 (4), 1977, pp. 250256.

[27] P. O'Kane, and O. Hargie, "Intentional and Unintentional Consequences of Substituting Face-to-Face Interaction with E-Mail: An Employee-Based Perspective", Interacting with Computers 19 (1), 2007, pp. 20-31.

[28] E. Otta, B.B. Lira, N.M. Delevati, O.P. Cesar, and C.S. Pires, "The Effect of Smiling and of Head Tilting on Person Perception", The Journal of Psychology 128 (3), 1994, pp. 323-331.

[29] U. Pavalanathan, and J. Eisenstein, "Emoticons Vs. Emojis on Twitter: A Causal Inference Approach", Proceedings of AAAI Spring Symposium on Observational Studies through Social Media and Other Human-Generated Content (OSSM).

[30] J.M. Reisman, "Journal of Personality Assessment", SACRAL: Toward the Meaning and Measurement of Friendliness 47 (4), 1983, pp. 405-413.

[31] E.J. Romero, and K.W. Cruthirds, "The Use of Humor in the Workplace", Academy of Management Perspectives 20 (2), 2006, pp. 58-69.

[32] P.H. Rossi, and A.B. Anderson, The Factorial Survey Approach: An Introduction, in P.H. Rossi and S.L. Nock (eds.), Measuring Social Judgments: The Factorial Survey Approach, Sage, Beverly Hills, CA, 1982, pp. 15-67.

[33] F. Schulz von Thun, Miteinander Reden 1 - Störungen und Klärungen: Allgemeine Psychologie der Kommunikation, rororo, Reinbek, DE, 2001.

[34] K. Skovholt, A. Grønning, and A. Kankaanranta, "The Communicative Functions of Emoticons in Workplace EMails: :-)", Journal of Computer-Mediated Communication 19 (4), 2014, pp. 780-797.

[35] P. Taesler, and M. Janneck, "Emoticons und Personenwahrnehmung: Der Einfluss von Emoticons auf die Einschätzung unbekannter Kommunikationspartner in der Online-Kommunikation", Gruppendynamik und Organisationsberatung 41 (4), 2010, pp. 375-384.

[36] I. Vandergriff, "Emotive Communication Online: A Contextual Analysis of Computer-Mediated Communication (CMC) Cues", Journal of Pragmatics 51 2013, pp. 1-12. 
[37] J.B. Walther, Theories of Computermediated Communication and Interpersonal Relations, in M.L. Knapp and J.A. Daly (eds.), The Handbook of Interpersonal Communication, Sage, Thousand Oaks, CA, 2011, pp. 443479 .

[38] P. Watzlawick, J.B. Bavelas, and D.D. Jackson, Pragmatics of Human Communication. A Study of Interactional Patterns, Pathologies, and Paradoxes, W. W. Norton \& Company, New York, NY, 2011.
[39] B. Wild, F.A. Rodden, A. Rapp, M. Erb, W. Grodd, and W. Ruch, "Humor and Smiling - Cortical Regions Selective for Cognitive, Affective, and Volitional Components", Neurology 66 (6), 2006, pp. 887-893.

[40] A. Wolf, "Emotional Expression Online: Gender Differences in Emoticon Use", CyberPsychology \& Behavior 3 (5), 2000, pp. 827-833. 